This is a postprint version of the following published document:

J.L. Cantero, J.Díaz- ÁLvarez, M.H. Miguélez, N.C. Marín. Analysis of tool wear patterns in finishing turning of Inconel 718. Wear 297(2013) $1-2$, pp.885-894.

Available at http://dx.doi.org/10.1016/j.wear.2012.11.004

(C) 2012 Elsevier

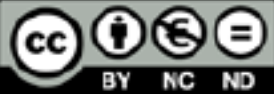

This work is licensed under a Creative Commons Attribution-NonCommercialNoDerivatives 4.0 International License. 


\title{
Analysis of tool wear patterns in finishing turning of Inconel 718
}

\author{
J.L. Cantero, J. Díaz-Álvarez, M.H. Miguélez*, N.C. Marín \\ Department of Mechanical Engineering, Universidad Carlos III de Madrid, Avda. de la Universidad 30, 28911 Leganés, Madrid, Spain
}

\begin{abstract}
This paper focuses on the analysis of tool wear mechanisms in finishing turning of Inconel 718, one of the most used Ni alloys, both in wet and dry cutting. Cemented carbides, ceramics and CBN tools are suitable for machining Ni alloys; coated carbide tools are competitive for machining operations of $\mathrm{Ni}$ alloys and widely used in industry. Commercial coated carbide tools (multilayer coating TiAl/ TiAlN recommended for machining $\mathrm{Ni}$ alloys) were studied in this work. The feasibility of two inserts tested for dry cutting of Inconel 718 has been shown in the work. Experimental test were performed in order to analyze wear patterns evolution. It was found great influence of side cutting edge angle in tool wear mode.
\end{abstract}

Keywords: Tool wear, Inconel 718, Notching, Chipping, Coated carbide tools.

\section{Introduction}

Nickel-based superalloys are widely used in aerospace applications due to their excellent mechanical properties maintained at high temperature and their corrosion resistance. Machining of these alloys is still a challenge, especially in aggressive conditions such as dry cutting. Characteristics of superalloys (high temperature tensile and shear strength, strong work hardening, reduced thermal conductivity, the trend to form built-up edge (BUE) and the presence of abrasive particles in their microstructures) induce severe thermo-mechanical loads at the tool-chip interface resulting in significant wear of the tool [1].

Tool wear strongly influences production costs and affect surface integrity of the component $[2,3]$.

Cutting tool selection is an important factor when machining $\mathrm{Ni}$ based alloys. Tool material should exhibit elevated wear resistance, high strength and toughness, high hardness at high temperature, chemical stability and thermal shock resistance. Cemented carbides have been used for decades and the use of multilayer coatings (TiN_TiCN_TiN) have improved their suitability for machining Ni-based alloys. Cemented carbide tools should not be used to machine nickel-based alloys at high speed since they cannot withstand the conditions of extreme high temperature and stress in the cutting zone. In general, the recommended cutting speeds range up to $30 \mathrm{~m} / \mathrm{min}$ for uncoated inserts and up to $100 \mathrm{~m} / \mathrm{min}$ when machining nickel-based alloys using cemented carbide tools properly coated [4]. Ceramic and

\footnotetext{
*Corresponding author. Tel.: +3491 6249402; fax: +34916249430.

E-mail address: mhmiguel@ing.uc3m.es (M.H. Miguélez).
}

CBN tools have superior hot hardness and can be used at speeds around an order of magnitude higher than the coated carbide cutting tools. Ceramic tools $\left(\mathrm{Al}_{2} \mathrm{O}_{3}-\mathrm{TiC}, \mathrm{Si}_{3} \mathrm{~N}_{4}\right.$ Sialon and $\mathrm{SiC}$ wisker reinforced $\mathrm{Al}_{2} \mathrm{O}_{3}$ ) have been used increasingly in cutting operations of $\mathrm{Ni}$ alloys. High cutting speed can be achieved with the use of wisker reinforced ceramics [5]. Cubic Boron Nitride (CBN) cutting tools give good performance and considerable increment in cutting speed when machining nickel-based alloys due to their notch wear resistance, however it should be considered their elevated cost [6,7]. Despite the advances in tool materials for cutting Ni alloys, coated cemented carbides are still competitive and widely used in industry.

Wear patterns observed in cutting tools results from the combined effect of different wear mechanisms involved in sliding friction occurring at the contact interface between tool, chip and machined surface (classical wear mechanisms are extensively analyzed in [8]). Ni alloys contains highly abrasive carbide particles causing abrasive wear. The low thermal conductivity and work hardening cause elevated temperature at the interface, up to $1200{ }^{\circ} \mathrm{C}$. High temperature promotes oxidation and diffusion wear. Also the high chemical affinity between workpiece and materials used for cutting tools enhances diffusion phenomena [9]. Moreover, welding and adhesion onto the cutting tool frequently observed during machining of $\mathrm{Ni}$ alloys, generate damage on the tool rake face [2].

Adhesion and work hardening are related with severe notching at the tool nose and/or the intersection between cutting edge and machined surface, being significant failure mode during machining Ni alloys with cemented carbide cutting tools. Abrasion at the clearance surface induces flank wear, chipping and catastrophic failure, also known as cause of tool rejection during machining of 
$\mathrm{Ni}$ alloys [10]. Burr formation commonly occurs as a consequence of work hardened layer, usually leading to catastrophic breakage of the insert edge [11].

The angle between the edge line and the longitudinal axis of the tool; side cutting edge angle ( $\kappa_{r}$ according to International Standard Organisation ISO 3685); influences tool performance during machining of Ni alloys. When $\kappa_{r}$ is increased the length of the edge in contact with the workpiece is larger and in consequence stresses and temperatures are diminished, since the forces and heat are distributed over a larger portion of the cutting edge.

Rahman et al. [12] analyzed the influence of tool geometry, cutting speed and feed rate on turning of Inconel 718. Machining forces, surface roughness and flank wear were considered as the performance indicators for tool life. Two types of inserts were used, based on cemented carbide substrate coated with TiN and $\mathrm{Al}_{2} \mathrm{O}_{3} \mathrm{CVD}$ respectively. They studied the effect of $\kappa_{r}$ on the tool life for three feeds $(0.2,0.3$ and $0.4 \mathrm{~mm} / \mathrm{rev})$ and three cutting speeds (30, 40 and $50 \mathrm{~m} / \mathrm{min}$ ), the depth of cut was fixed to $2 \mathrm{~mm}$. For both types of inserts, tool life increases as $\kappa_{r}$ increases (in the range $5^{\circ}$ to $45^{\circ}$ and the temperature of the tool-chip interface related to the undeformed chip thickness decreases). Heat removal from the cutting edge was improved when the heat generated during the cutting process is distributed over a greater length of the cutting edge. Moreover the distribution of the cutting forces over a larger portion of the cutting edge reduces tool notching and substantially improves tool life.

Although the exact details of various investigations on notch formation during machining do not agree completely, it is possible to deduce a general conclusion: in order to minimize notching it is recommended to use a cutting tool with a large side cutting edge angle and negative rake angle [10].

Surface coatings are usually used in cutting tools for low machinability materials such as $\mathrm{Ni}$ superalloys. Coated tools outperform the behavior of the substrate especially when the cutting speed increases [13].

The TiAlN family of PVD coatings, with a favorable combination of hardness and oxidation stability at elevated temperatures, is one of the most used coatings for hard to cut materials [14] showing improved tool life under conditions of machining of aerospace alloys [15]. Jindal et al. [16] found that TiAlN coated tools exhibited good cutting performance when turning Inconel 718, AISI 1045 steel and ductile iron at low- and high-cutting speed conditions.

These coatings also typically have low thermal conductivity, which protects the tool surface from heat transfer however this fact could be negative for surface integrity due to the increased amount of heat transferred to the workpiece [17].

Main drawback of these PVD coatings is a lack of high temperature lubricity. As a result the adhesive wear mechanism is not fully addressed by applying this coating; this problem has motivated the recent development of adaptive hard coatings [18].

TiAlN is commonly used in combination with TiN, since multilayered coatings have mechanical advantages over single layer composed of either TiN or TiAlN [19]. TiAlN is also combined with $\mathrm{MoS}_{2}$ because of its lubricating properties or with $\mathrm{CrN}$ on account of its reduced tendency to weld to the workmaterial, improving resistance to adhesive wear [20].

Despite the aggressive conditions occurring during machining of Ni alloys for both tool and workpiece, dry cutting of this family of materials is desirable due to economical and environmental reasons. Global cost associated to coolant (acquisition, use, disposal and the cleaning of workpieces) is significant, up to four times the one of cutting tools used in cutting operations [21]. Coolants are widely used for disposal of chip, improvement of machining accuracy and surface finish, and extension of tool life, especially in aggressive cutting conditions. Dry cutting is the best technique under the point of view of non generation of residual cutting fluid and Minimal Quantity Lubrication(MQL) involves significant reduction of industrial waste.

Settineri et al. [22] applied the coatings, TiN+AlTiN, $\mathrm{TiN}+\mathrm{AlTiN}+\mathrm{MoS}_{2}$ and $\mathrm{CrN}+\mathrm{CrN}: \mathrm{C}+\mathrm{C}$, by PVD techniques on WC-Co inserts, in order to compare their performance in machining experiments in dry and MQL turning of Inconel 718. The decreasing performance order of the coatings (TiN+AlTiN + MoS2, followed by $\mathrm{TiN}+\mathrm{AlTiN}$, and finally $\mathrm{CrN}+\mathrm{CrN}: \mathrm{C}+\mathrm{C}$ ) was obtained from experiments and tool wear analysis. MQL was found to enhance tool performances, further limiting friction. Wear analysis obtained using SEM-EDS technique showed mainly abrasion and welding wear mechanisms. A large amount of built up edge was found on the cutting edge in all tools analyzed, leading in some cases to craterization and delamination.

Devillez et al. [23] studied the effect of dry machining on surface integrity. Wet and dry turning tests were performed at various cutting speeds, with semi-finishing conditions $(0.5 \mathrm{~mm}$ depth of cut and $0.1 \mathrm{~mm} / \mathrm{rev}$ feed rate) and using a coated carbide tool. A cutting speed equal to $60 \mathrm{~m} / \mathrm{min}$ was stated as an optimal value in dry machining: acceptable surface quality with residual stresses and microhardness values in the machining affected zone of the same order than those obtained in wet conditions were obtained and no severe microstructure alteration was detected. The trend to form built up edge is reduced or canceled in the case of wet cutting, because tool surfaces are cooler than in dry cutting preventing the adhesion tool wear. Notch wear at the depth of cut and flank wear were also observed in the carbide tool with coating $\mathrm{TiCN}-\mathrm{Al}_{2} \mathrm{O}_{3}-\mathrm{TiN}$.

This paper focuses on the analysis of mechanisms and evolution of tool wear when turning Inconel 718, one of the most significant Ni alloys, both in wet and dry cutting. Scientific works in the literature show that dry cutting of $\mathrm{Ni}$ alloys is possible although elevated wear rate is involved in such conditions. Commercial coated carbide tools (multilayer coating TiAl/TiAlN recommended for machining $\mathrm{Ni}$ alloys) were analyzed, with different cutting geometries.

\section{Experimental work}

Turning tests were carried out in a lathe Pinacho Smart turn 6/165 equipped with a dynamometer Kistler 9257B for cutting force measurement (with both in fresh and worn inserts).Workpiece was a disc (diameter $150 \mathrm{~mm}$, thickness $20 \mathrm{~mm}$ ) of Inconel Alloy 718 annealed $968{ }^{\circ} \mathrm{C}$ held for $50 \mathrm{~min}$, water cooled. The longitudinal tool axis was positioned parallel to the lathe axis (see Fig. 1). Tool displacement direction was orthogonal to the lathe axis with constant cutting speed.

The workpiece was previously machined with a cutting insert different to those used during the tests. This methodology introduces an uncertainty in the establishment of the depth of cut especially significant when a small value of depth is considered ( $0.5 \mathrm{~mm}$ in this case). An experimental device (see Fig. 1) based on a precise dial depth gage (Mitutoyo ref. 3109, resolution $0.001 \mathrm{~mm}$ ) was installed in the lathe, allowing the measurement of effective depth of cut in each pass.

Surface quality was analyzed using a device Mitutoyo Serie 178 modelo SJ-201 for roughness measurement.

Three commercial carbide diamond shaped cutting inserts [24], were used for finishing turning of Inconel 718 both in wet and dry cutting. All inserts were positive (horizontally positioned on the tool holder), with tip angle equal to $80^{\circ}$ and tip radius equal to $0.4 \mathrm{~mm}$. Two different carbide substrates (CP500 and TS2000) were tested while the same multilayer coating (inner layer TiAlN and external layer TiN) was used in all inserts. Both substrates are recommended 
by the tool manufacturer for finishing operations of low machinability alloys. CP500 is a very tough micrograin hard metal intended for finishing and medium roughing of thermo-resistant alloys. TS2000 based on micro-grains is principally intended for finishing operations on superalloys.

Two different configurations of the cutting edge $\left(E_{1}\right.$ and $\left.E_{2}\right)$ suitable for finishing turning of superalloys, were considered for the inserts based on substrate TS2000. The inserts based on CP500 substrate had the configuration $\mathrm{E}_{1}$. Fig. 2 shows schematically edge configurations $\mathrm{E}_{1}$ (a sharp cutting edge that gives easy-cutting properties) and $E_{2}$ (robust and proper for finishing operations).

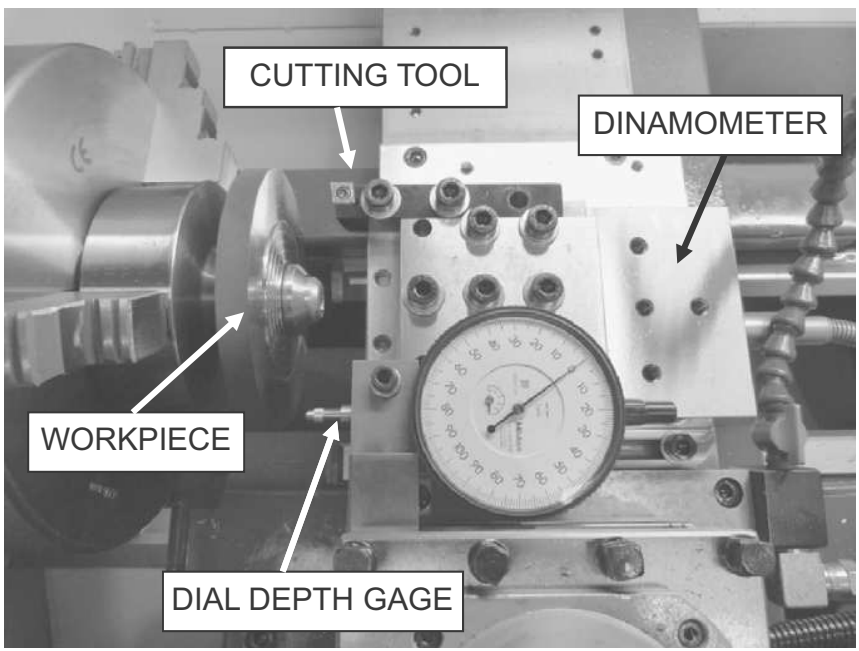

Fig. 1. Lathe instrumented for measurement of cutting force and effective depth of cut.
The configurations material/geometry of the insert previously described were positioned in the tool holder with $\kappa_{r}$ equal to $0^{\circ}$. After preliminary tests showing the good performance of material TS2000 with geometry $E_{1}$, for the finishing operation, it was decided to check this configuration also with $\kappa_{r}$ equal to $45^{\circ}$ in order to evaluate the enhancement of performance (see Fig. 3). Thus four different insert configurations denoted in the following $\mathrm{T}_{1}, \mathrm{~T}_{2}, \mathrm{~T}_{3}$ and $\mathrm{T}_{4}$ were tested (see Table 1 ).

Cutting tests were carried out with coolant and in dry conditions. The cutting parameters were established in the range of tool manufacturer recommendations for the use of cutting inserts with coolant. Dry cutting is more aggressive, thus the recommended parameters for wet cutting could be excessive for dry tests. However in order to compare results, the same parameters were stated for all conditions analyzed, in consequence reduced tool life is obtained in some cases as will be shown in the next section. The tools with very short lives have no practical interest for industry and the cutting speed should be reduced when used in especially aggressive conditions.

Dry and lubricated finishing turning were carried out with the following cutting parameters: depth of cut $0.5 \mathrm{~mm}$, feed rate $0.1 \mathrm{~mm} / \mathrm{rev}$, cutting speed 50 and $70 \mathrm{~m} / \mathrm{min}$. Thus tests were performed for each insert in four different conditions: with and

Table 1

Insert configurations used in turning tests.

\begin{tabular}{lllll}
\hline Tool & Coating & Subtrate & Cutting edge & $\kappa_{r}$ \\
\hline $\mathrm{T}_{1}$ & TiAIN/TiN & CP500 & $\mathrm{E}_{1}$ & $0^{\circ}$ \\
$\mathrm{T}_{2}$ & TiAlN/TiN & TS2000 & $\mathrm{E}_{1}$ & $0^{\circ}$ \\
$\mathrm{T}_{3}$ & TiAIN/TiN & TS2000 & $\mathrm{E}_{2}$ & $0^{\circ}$ \\
$\mathrm{T}_{4}$ & TiAIN/TiN & TS2000 & $\mathrm{E}_{1}$ & $45^{\circ}$ \\
\hline
\end{tabular}
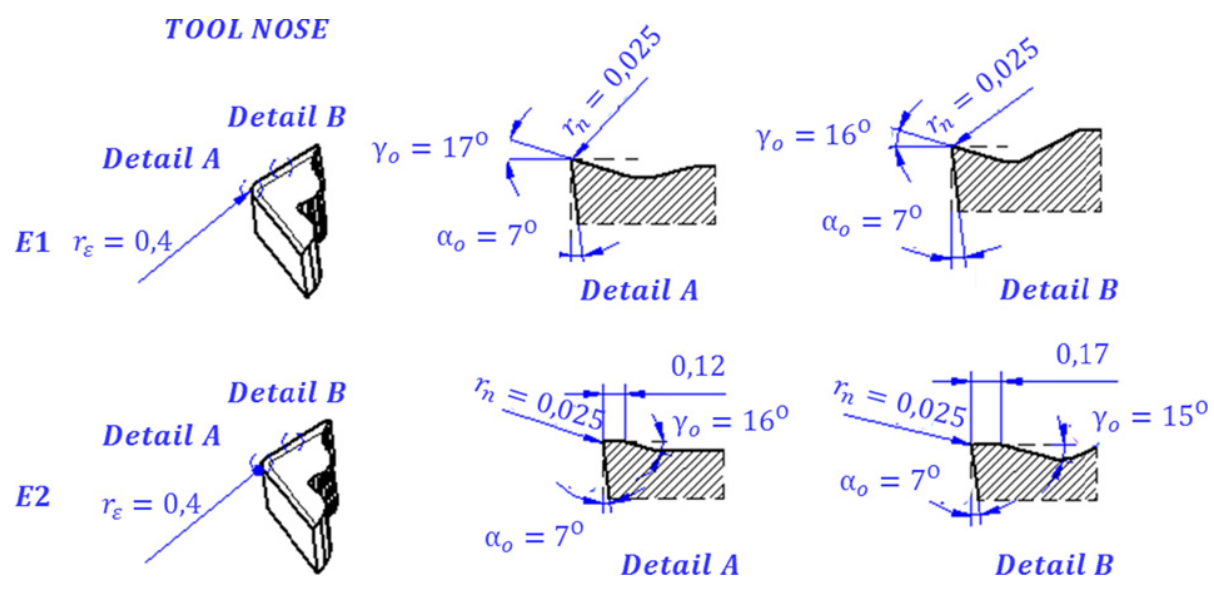

Fig. 2. Edge configurations $E_{1}$ and $E_{2}$ (courtesy by SECO).

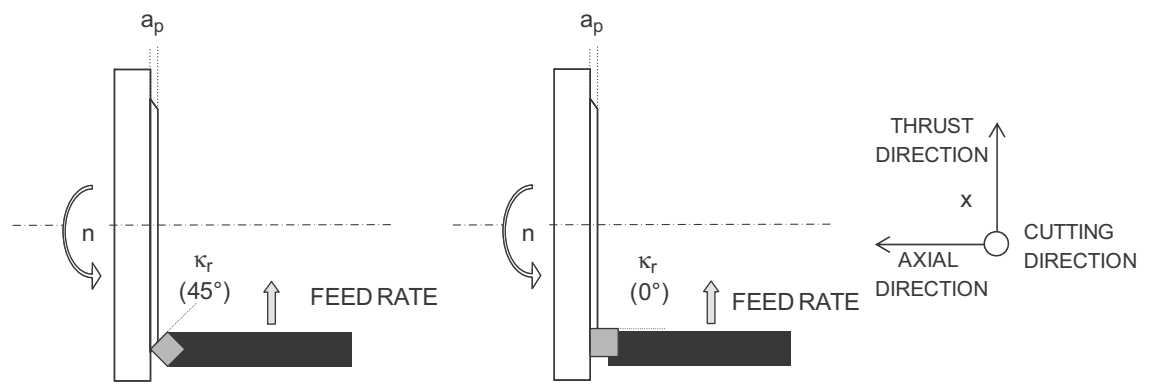

Fig. 3. Scheme of $\kappa_{r}$ during turning tests. 
without coolant and two cutting speeds (50 and $70 \mathrm{~m} / \mathrm{min}$ ). Cutting forces and real depth of cut were measured in each test. Turning tests were systematically stopped in order to analyze wear evolution using optical microscope and SEM-EDS technique was used to verify the initial geometry of the fresh cutting edge and to analyze the final state of wear at the end of tool life.

\section{Results and discussion}

\subsection{Cutting forces}

As was explained in Section 2, the depth of cut was verified after each pass. Forces were normalized for the nominal value of $0.5 \mathrm{~mm}$, multiplying the measured value of the force by the ratio between the nominal depth of cut and the actual value of the depth of cut.

The components of the cutting force in directions of cutting speed, feed and depth of cut are denoted cutting force $F_{c}$, thrust force $F_{t}$, and axial force $F_{a}$, respectively. Forces measured during turning tests are summarized in Fig. 4.

Fresh tools: Small differences (less than 5\%) in all components of cutting force were observed for fresh tools $T_{1}$ and $T_{2}$. The component $F_{c}$ was also similar for tools $\mathrm{T}_{3}$ and $\mathrm{T}_{4}$. However higher values of $F_{t}$ and $F_{a}(10-25 \%)$ were found for the tool $\mathrm{T}_{3}$ (corresponding with the cutting edge $E_{2}$ with decreased effective rake angle) when compared with $T_{1}$ and $T_{2}$. The tool $T_{4}$ showed a significant increment (70-120\%) in the component $F_{t}$ because of the inclination of the cutting edge and the enhanced specific cutting force due to the change of edge position $\left(45^{\circ}\right)$ leading to decreased chip thickness. Increasing the ratio between edge radius and effective chip thickness, results in higher levels of specific force.
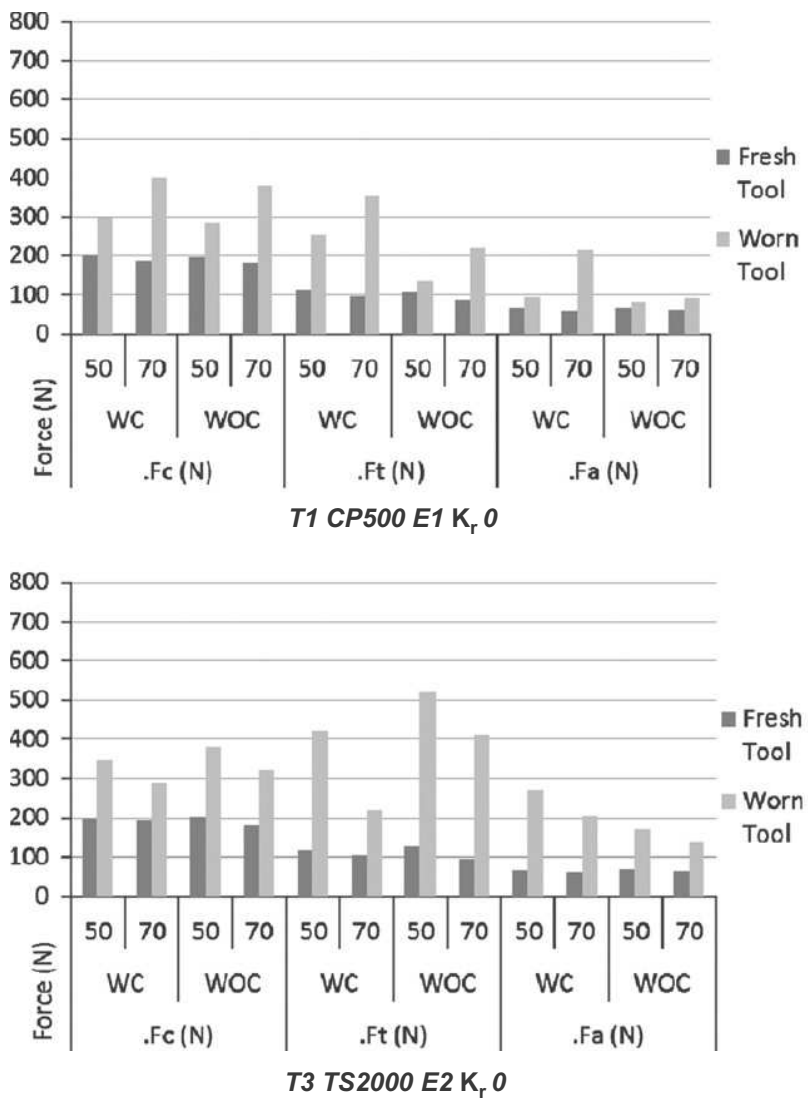

The influence of coolant in cutting force when machining with fresh tool could be considered negligible: the level of force is approximately the same in dry conditions and using coolant.

Worn tools: Different wear mechanisms were observed, mainly notch wear, flank wear, workpiece material adhesion (built up edge, BUE), chipping at the cutting edge. Thus the end of tool life criterion in each case corresponds with different geometrical configuration of the worn tool, and in consequence it is not easy to observe clear trends concerning cutting forces at the final wear stages of the tools. It should be noted that the forces for worn tool were obtained at the end of tool life. On the other hand, the establishment of tool lives for different wear mechanisms leads to different wear stages of the tool at the end of life. These facts complicate the interpretation of cutting forces trends for worn tool.

Some common characteristics were observed during the tests. As it is commonly observed in machining tests, cutting forces were higher for worn tools when compared with those obtained for new inserts. In general these variations were larger when coolant was used. Cutting force $F_{c}$ was larger for worn tool than for fresh tool (between 50 and $115 \%$ with coolant and between $40-110 \%$ in dry cutting). Radial and axial components $\left(F_{t}\right.$ and $\left.F_{a}\right)$ showed much larger increments (between 40 and 400\% with coolant and between 20 and 360\% in dry cutting).

Forces for worn $\mathrm{T}_{4}$ insert were more elevated than those observed for $T_{2}$, especially the axial component of the force. These observations are related to the lower uncut chip thickness with $\kappa_{r} 45^{\circ}$ causing and enhanced influence of the damaged cutting edge on the cutting forces.

\subsection{Wear evolution}

Different wear mechanisms commonly associated to machining of $\mathrm{Ni}$ alloys were observed during the wear tests, being
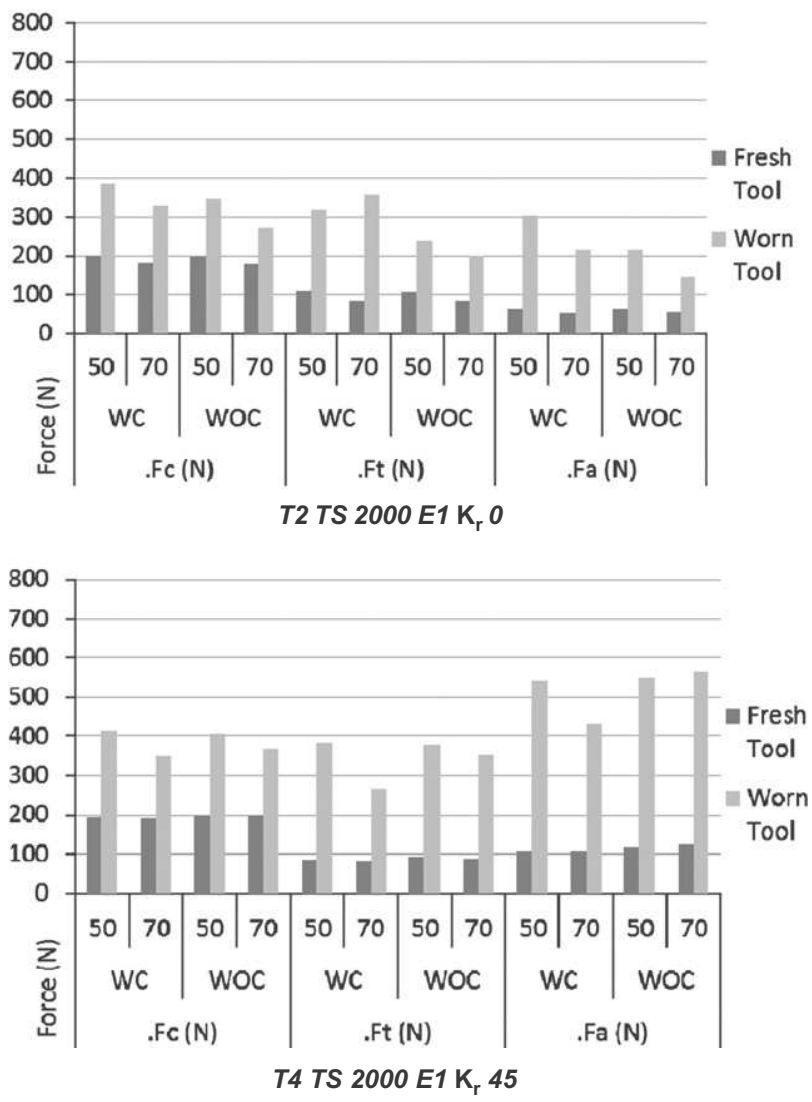

Fig. 4. Cutting forces measured during turning tests with coolant (WC) and without coolant (WOC). 
notching and chipping the most significant modes [25]. Also material adhesion was observed in all cases analyzed involving a difficult identification of dominant wear mechanisms and levels of wear. Mainly notch wear, but also flank wear, chipping at the cutting edge and BUE were found, sometimes combined in the same insert; thus different end of tool life criteria had to be established.

As was explained in the introduction, notching at the tool tip and depth of cutting zone is a common failure mode when machining nickel-based alloys. Notch formation results from a combination of aggressive conditions involved during machining process of $\mathrm{Ni}$ alloys: high temperature, elevated strength and strain hardening of the workpiece maintained at high temperature and the abrasive chips [26].

Material behavior also influences chip morphology and surface quality. Chip separates with a significant lateral plastic flow of workpiece material at the edge of the shear zone, causing burr formation (excessive burr formation is included as a criterion of tool rejection).

Flank wear, chipping and catastrophic failure are other causes of tool rejection when machining nickel-based alloys. Tool failures caused by flank wear and also crater wear (crater is commonly observed at elevated cutting speed) may be partly attributed to the diffusion wear mechanism. Machining at high speed accelerates the diffusion process due to excessive heat generation. Crater wear is not observed in the range of cutting speed analyzed in the present work.

Chipping, or fracture of the tool edge is also observed during machining of nickel-based, being reported as the dominant mechanism when milling Inconel 718 and Nimonic 75 [25]. Tool fracture is directly related with attrition wear (the removal of grains from tool material by the work material, producing a rough area) and thermal cracking occurring at high temperatures [27]. The intrinsic characteristics of $\mathrm{Ni}$ alloys cutting; such as the irregular flow of work material against the cutting edge, chip segmentation inducing variable forces and in consequence, fatigue, and also thermo-mechanical fatigue leading to cracking; are the origin of attrition. The low thermal conductivity of the coating TiAlN (used in the inserts in the present work) limits heat dissipation and generates high thermal gradients that may lead to thermal cracks, especially if residual stresses are present in the coating. In the case of multilayer coating (as it is the case of the inserts used in the tests of this work) residual stresses are likely to be present.

It is worth to note that the wear mechanisms are not independent: they are interrelated. Adhesion of the workpiece material causing built-up edge (BUE) formation tends to promote tool chipping (removal of relatively large discrete particles of tool material), since BUE is never completely stable, but it periodically breaks off taking with it a small lump of tool edge. Notch wear is a type of combined flank and rake face wear occurring adjacent to the point where the major cutting edge intersects the work surface. It is common in machining of materials with high work-hardening characteristics including many stainless steels and heat-resistant nickel or chromium alloys, as it is the case of Inconel 718.

In the following paragraphs the evolution of wear modes is discussed and the information corresponding to each case is summarized in Tables 2-5. The measurement of wear was carried out according to International Standard Organisation ISO 3685. The standard divides the edge in several zones (zone $C$ is the curved part of the cutting edge at the tool corner, zone $B$ is the remaining straight part of the cutting edge between zone $C$ and zone $A$, zone $A$ is the quarter of the worn cutting edge length farthest away from the tool corner). $\mathrm{VB}_{A}, \mathrm{VB}_{B}$ max and $\mathrm{VB}_{\mathrm{C}}$ denote respectively the maximum width of the flank wear land at zone $A$, $\mathrm{B}$ and $\mathrm{C}$. Zone $\mathrm{N}$ extends beyond the area of mutual contact between the tool and workpiece; the wear is of notch type and it is quantified by the maximum width of the notch, $\mathrm{VB}_{N}$.

The measurements presented in this section correspond to $\mathrm{VB}_{B}$ $\max$ and $\mathrm{VB}_{N}$ in cases corresponding to flank wear and notch, respectively. When the standard notation is not directly applicable, for instance insert showing chipping or breakage, wear extension is quantified with chipping or fracture length. Figs. 5-10 illustrate

Table 2

Wear evolution and tool life of $\mathrm{T}_{1}\left(\mathrm{CP} 500 \mathrm{E} 1 \kappa_{r} 0\right)$.

\begin{tabular}{|c|c|c|c|c|}
\hline \multirow[t]{2}{*}{ Tool $T_{1}$} & \multicolumn{2}{|l|}{ Coolant } & \multicolumn{2}{|l|}{ Dry } \\
\hline & $V=50 \mathrm{~m} / \mathrm{min}$ & $V=70 \mathrm{~m} / \mathrm{min}$ & $V=50 \mathrm{~m} / \mathrm{min}$ & $V=70 \mathrm{~m} / \mathrm{min}$ \\
\hline $\begin{array}{l}\text { Intermediate } \\
\text { level of wear }\end{array}$ & $\begin{array}{l}\text { Chipping, BUE and notch wear } \\
\text { (rapid progression) } \\
t_{c}=1.5 \text { min; } \mathrm{VB}_{N}=0.2 \mathrm{~mm}\end{array}$ & $\begin{array}{l}\text { Chipping, BUE and notch wear } \\
\text { (rapid progression) } \\
t_{c}=1 \mathrm{~min} ; \mathrm{VB}_{N} 0.2 \mathrm{~mm}\end{array}$ & $\begin{array}{l}\text { Chipping, BUE and notch } \\
\text { (rapid progression) }\end{array}$ & $\begin{array}{l}\text { Chipping, BUE and notch wear } \\
\text { (rapid progression) }\end{array}$ \\
\hline$T$ (Tool life) & $\begin{array}{l}T=5 \text { min due to notch wear inducing } \\
\text { cutting edge breakage }\end{array}$ & $\begin{array}{l}T=4.5 \mathrm{~min} \text { due to notch wear } \\
\text { inducing cutting edge breakage }\end{array}$ & $\begin{array}{l}T=1 \mathrm{~min} \text { due to notch wear } \\
\text { inducing cutting edge breakage }\end{array}$ & $\begin{array}{l}T=2 \text { min due to notch wear } \\
\text { inducing cutting edge breakage }\end{array}$ \\
\hline
\end{tabular}

Table 3

Wear evolution and tool life of $\mathrm{T}_{2}$ (TS2000 $\mathrm{E}_{1} \kappa_{r} 0$ ).

\begin{tabular}{|c|c|c|c|c|}
\hline \multirow[t]{2}{*}{ Tool $\mathbf{T}_{2}$} & \multicolumn{2}{|l|}{ Coolant } & \multicolumn{2}{|l|}{ Dry } \\
\hline & $V=50 \mathrm{~m} / \mathrm{min}$ & $V=70 \mathrm{~m} / \mathrm{min}$ & $V=50 \mathrm{~m} / \mathrm{min}$ & $V=70 \mathrm{~m} / \mathrm{min}$ \\
\hline $\begin{array}{l}\text { Intermediate } \\
\text { level of wear }\end{array}$ & $\begin{array}{l}t_{c}=1.5 \mathrm{~min} \text {; Chipping, BUE and notch } \\
\text { wear. } t_{c}=12 \mathrm{~min} \text {; Notch } \mathrm{VB}_{N}=0.3 \mathrm{~mm} \text {. } \\
\text { Noise and vibrations due to chipping }\end{array}$ & $\begin{array}{l}t_{c}=1 \mathrm{~min} \text {; Chipping, BUE and } \\
\text { notch wear. Rapid } \\
\text { progression of chipping and } \\
\text { notching }\end{array}$ & $\begin{array}{l}\text { BUE since early stages of the test Flank } \\
\text { wear }\left(t_{c}=2.5 \text { min, flank } \mathrm{VB}_{B}\right. \\
\text { max }=0.2 \mathrm{~mm}) . \text { Moderate chipping and } \\
\text { notch wear }\end{array}$ & $\begin{array}{l}\text { Rapid chipping, BUE and notch wear } \\
\text { rapid progression. } t_{c}=1 \mathrm{~min} \text {; Notch } \\
\mathrm{VB}_{N}=0.25 \mathrm{~mm} \text {. High level of } \\
\text { vibrations }\end{array}$ \\
\hline T (Tool life) & $\begin{array}{l}T=15 \mathrm{~min} \text {, due to cutting edge } \\
\text { breakage induced by chipping }\end{array}$ & $\begin{array}{l}T=5 \text { min, due to cutting } \\
\text { edge breakage induced by } \\
\text { chipping }\end{array}$ & $\begin{array}{l}T=9.5 \mathrm{~min} \text {, due to flank wear reaching } \\
\mathrm{VB}_{B} \max =0.4 \mathrm{~mm}\end{array}$ & $\begin{array}{l}T=2 \text { min, due to cutting edge } \\
\text { breakage induced by chipping }\end{array}$ \\
\hline
\end{tabular}


Table 4

Wear evolution and tool life of $\mathrm{T}_{3}\left(\mathrm{TS} 2000 \mathrm{E}_{2} \kappa_{r} 0\right)$.

\begin{tabular}{|c|c|c|c|c|}
\hline \multirow[t]{2}{*}{ Tool $\mathbf{T}_{3}$} & \multicolumn{2}{|l|}{ Coolant } & \multicolumn{2}{|l|}{ Dry } \\
\hline & $V=50 \mathrm{~m} / \mathrm{min}$ & $V=70 \mathrm{~m} / \mathrm{min}$ & $V=50 \mathrm{~m} / \mathrm{min}$ & $V=70 \mathrm{~m} / \mathrm{min}$ \\
\hline \multirow[t]{2}{*}{$\begin{array}{l}\text { Intermediate level of } \\
\text { wear }\end{array}$} & $t_{c}=1 \mathrm{~min} ;$ Chipping and BUE & $t_{c}=1$ min; Chipping and BUE & $\begin{array}{l}t_{c}=1.5 \mathrm{~min} ; \text { Chipping, BUE and } \\
\text { notch wear }\end{array}$ & $\begin{array}{l}t_{c}=1.5 \mathrm{~min} \text {; Chipping, BUE and } \\
\text { notch wear }\end{array}$ \\
\hline & $\begin{array}{l}t_{c}=5 \mathrm{~min} ; \text { Notch wear } \\
\mathrm{VB}_{N}=0.25 \mathrm{~mm}\end{array}$ & $\begin{array}{l}t_{c}=2 \mathrm{~min} ; \text { Notch wear } \\
\mathrm{VB}_{N}=0.15 \mathrm{~mm}\end{array}$ & Rapid progression of notch wear & Rapid progression of notch wear \\
\hline T (Tool life) & $\begin{array}{l}T=9 \mathrm{~min} \text { due to notch reaching } \\
\mathrm{VB}_{N}=0.4 \mathrm{~mm}\end{array}$ & $\begin{array}{l}T=6 \mathrm{~min} \text { due to notch reaching } \\
\mathrm{VB}_{N}=0.4 \mathrm{~mm}\end{array}$ & $\begin{array}{l}T=6 \mathrm{~min} \text { due to notch reaching } \\
\mathrm{VB}_{N}=0.4 \mathrm{~mm}\end{array}$ & $\begin{array}{l}T=4.5 \mathrm{~min} \text { due to notch reaching } \\
\mathrm{VB}_{N}=0.4 \mathrm{~mm}\end{array}$ \\
\hline
\end{tabular}

Table 5

Wear evolution and tool life of $\mathrm{T}_{4}\left(\mathrm{TS} 2000 \mathrm{E}_{1} \kappa_{r} 45\right)$.

\begin{tabular}{|c|c|c|c|c|}
\hline \multirow{2}{*}{ Tool $T_{4}$} & \multicolumn{2}{|l|}{ Coolant } & \multicolumn{2}{|l|}{ Dry } \\
\hline & $V=50 \mathrm{~m} / \mathrm{min}$ & $V=70 \mathrm{~m} / \mathrm{min}$ & $V=50 \mathrm{~m} / \mathrm{min}$ & $V=70 \mathrm{~m} / \mathrm{min}$ \\
\hline $\begin{array}{l}\text { Intermediate } \\
\text { level of wear }\end{array}$ & $\begin{array}{l}\text { Progressive flank wear }\left(t_{c}=1.5 \mathrm{~min} \text {, }\right. \\
\left.\text { flank } \mathrm{VB}_{B \max }=0.15 \mathrm{~mm}\right) \\
\text { BUE and notch wear not observed }\end{array}$ & $\begin{array}{l}\text { Chipping since early stages of the } \\
\text { test } \\
\text { BUE and notch wear not observed }\end{array}$ & $\begin{array}{l}\text { Progressive flank wear }\left(t_{c}=1 \mathrm{~min} \text {, }\right. \\
\left.\text { flank } \mathrm{VB}_{B} \max =0.15 \mathrm{~mm}\right) \\
\text { BUE and notch wear not observed }\end{array}$ & $\begin{array}{l}\text { Chipping since early stages of the } \\
\text { test } \\
\text { Notch wear not observed } \\
\text { BUE initiation at } t_{c}=3 \mathrm{~min}\end{array}$ \\
\hline T (Tool life) & $\begin{array}{l}\text { Moderate chipping for } t_{c}>15 \mathrm{~min} \text {. } \\
T=30.5 \text { min, due to flank wear } \\
\text { reaching flank } \mathrm{VB}_{B \text { max }}=0.4 \mathrm{~mm}\end{array}$ & $\begin{array}{l}\text { Moderate flank wear } \\
T=6.5 \text { min, due to cutting edge } \\
\text { breakage induced by chipping }\end{array}$ & $\begin{array}{l}\text { Moderate chipping for } t_{c}>12 \mathrm{~min} \\
T=22 \mathrm{~min} \text {, due to flank wear } \\
\text { reaching flank } \mathrm{VB}_{B \max }=0.4 \mathrm{~mm}\end{array}$ & $\begin{array}{l}\text { Moderate flank wear. } \\
T=4 \text { min due to cutting edge } \\
\text { breakage induced by chipping }\end{array}$ \\
\hline
\end{tabular}

wear patterns observed during turning tests. In all cases it is shown an advanced stage of wear progression, thus the coating has been lost in the worn zone.

\subsubsection{Tool $T_{1}\left(C P 500 E_{1} \kappa_{r} 0\right)$}

Tool CP500 exhibited strong chipping and notch wear. Excessive notch wear and cutting edge deterioration lead to cutting edge breakage in all cases tested. Tool life was around $2 \mathrm{~min}$ in dry conditions and 5 min with coolant, in industrial applications, this tool should be used at lower velocities in order to improve tool life. Fig. 5 illustrates primary cutting edge breakage due to previous notch wear.

High temperature and pressure induced rapid wear evolution for the substrate CP500 tougher but less hard than TS2000. Cutting forces increased due to the alteration of cutting edge accelerating wear progression.

Wear description is summarized for $T_{1}$ in Table 2 .

\subsubsection{Tool $T_{2}\left(T S 2000 E_{1} \kappa_{r} 0\right)$}

During turning tests carried out with coolant (cutting speed 50 and $70 \mathrm{~m} / \mathrm{min}$ ) early chipping was observed, associated with BUE, and also notch wear. Both wear modes progressively increased with cutting time, being faster for the velocity $70 \mathrm{~m} / \mathrm{min}$. Chipping caused cutting force increment and also induced vibrations and noise (chipping is illustrated in Fig. 6). Finally chipping evolved causing edge breakage (see Fig. 7) for cutting time $15 \mathrm{~min}$ (at $50 \mathrm{~m} / \mathrm{min}$ ) and $5 \mathrm{~min}$ (at $70 \mathrm{~m} / \mathrm{min}$ ) respectively. For cutting time close to the end of tool life also elevated notch wear was observed (notch depth was measured ranging between 0.3 and $0.35 \mathrm{~mm}$ ).

Dry turning tests involved not only notch (notching is illustrated in Fig. 8) and chipping, also significant flank wear was observed, due to higher level of temperature increasing abrasion. At low velocity $(50 \mathrm{~m} / \mathrm{min})$ flank wear was the dominant mode reaching $0.4 \mathrm{~mm}$ for cutting time $9.5 \mathrm{~min}$. In these tests also chip hammering was observed leading to primary edge breakages however they did not affect the whole integrity of the insert. At higher velocity $(70 \mathrm{~m} / \mathrm{min})$ chipping and notch wear rapidly progressed reaching the end of tool life for cutting time equal to $2 \mathrm{~min}$ due to breakage resulting from chipping. Velocity $70 \mathrm{~m} / \mathrm{min}$ seems to be too high for industrial dry turning with tool T2. The low value of cutting time did not allow the progression of flank wear (flank depth was around $0.15 \mathrm{~mm}$ ).

For both dry and wet cutting, chipping wear is significantly increased when cutting speed increases from 50 to $70 \mathrm{~m} / \mathrm{min}$. This effect results in a strong reduction of tool life at cutting speed equal to $70 \mathrm{~m} / \mathrm{min}$.

The information concerning wear evolution of $T_{2}$ is summarized in Table 3.

\subsubsection{Tool $T_{3}\left(T S 2000 E_{2} \kappa_{r} 0\right)$}

Both edge geometries $\left(E_{1}\right.$ and $\left.E_{2}\right)$ tested in this work have positive rake angle as it is usually stated for finishing operations. However in order to strengthen the edge, $E_{2}$ configuration includes a chamfer giving a local negative rake angle. In consequence the geometry $E_{2}$ is more robust than $E_{1}$, being a positive aspect for both chipping and notch wear resistance observed during test turning with $E_{1}$. However negative rake angle is also related with larger deformation and temperature and also with an increased occurrence of vibrations. These facts could be especially significant during machining of Inconel 718 due to its excellent mechanical properties exhibited even at high temperature. In fact cutting forces measured in the tests were $10 \%$ higher in the case of $E_{2}$ than in the case of $E_{1}$.

Tool wear modes were similar for the inserts with edge configuration $E_{1}$ and $E_{2}$. However, for the conditions analyzed in this work, the use of the robust edge configuration $E_{2}$ increases edge resistance to chipping.

The level of the wear increased with the aggressiveness of the operation: dry turning and higher velocity $(70 \mathrm{~m} / \mathrm{min})$. In that case, even for low cutting time (1-2 min) it was possible to observe significant levels of chipping and notch wear and BUE at the primary edge. Also the secondary cutting edge was affected showing small breakages (they did not progress up to insert failure risk) due to chip hammering (this effect is illustrated in Fig. 9). 


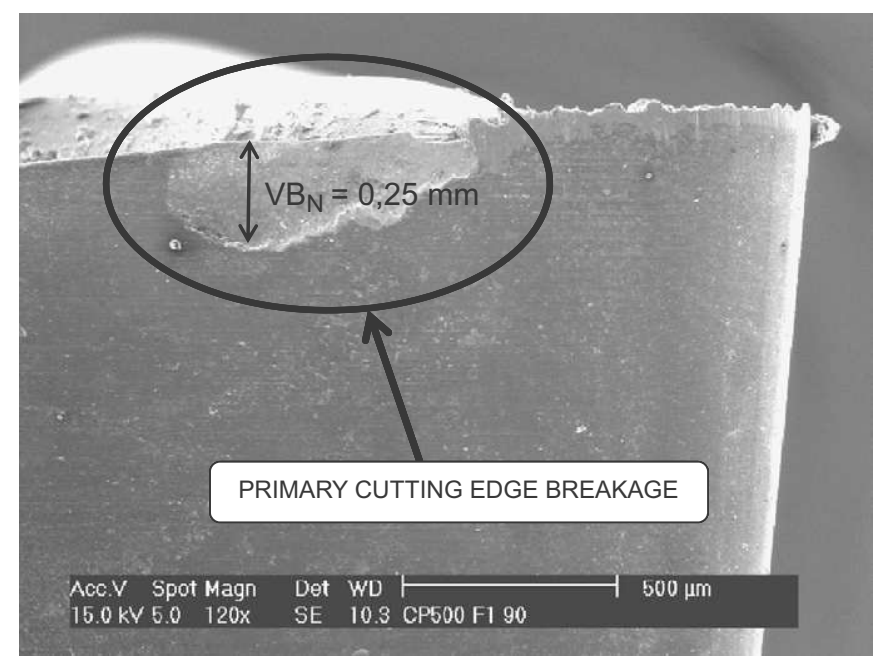

Fig. 5. Primary cutting edge breakage detail due to a previous notch wear corresponding to $\mathrm{T}_{1}\left(\mathrm{E}_{1} \mathrm{CP} 500 \kappa_{r} 0\right)$ worn insert tested without coolant to a cutting speed of $70 \mathrm{~m} / \mathrm{min}$.

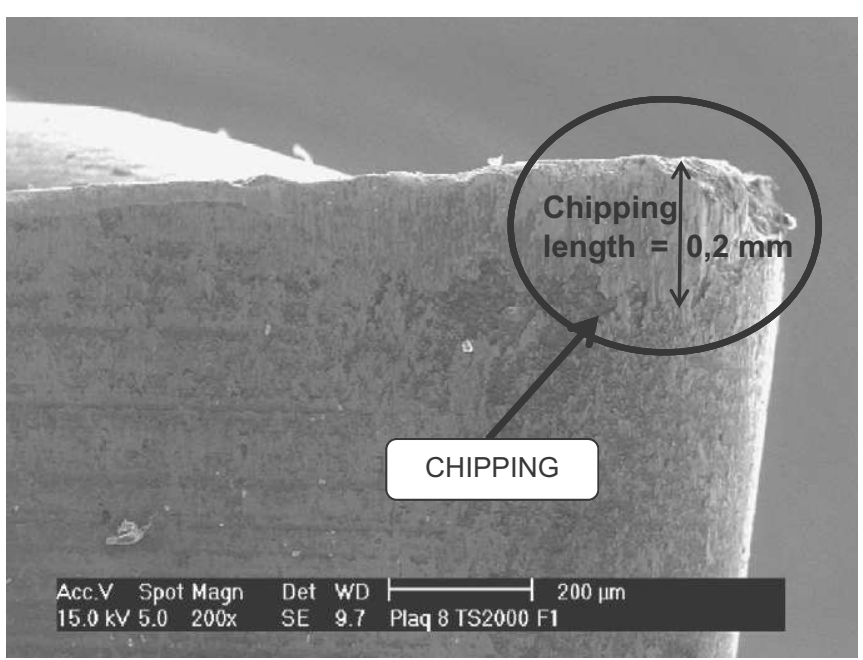

Fig. 6. Chipping detail corresponding to $\mathrm{T}_{2}\left(\mathrm{E}_{1} \mathrm{TS} 2000 \kappa_{r} 0\right)$ worn insert tested with coolant at cutting speed of $70 \mathrm{~m} / \mathrm{min}$.

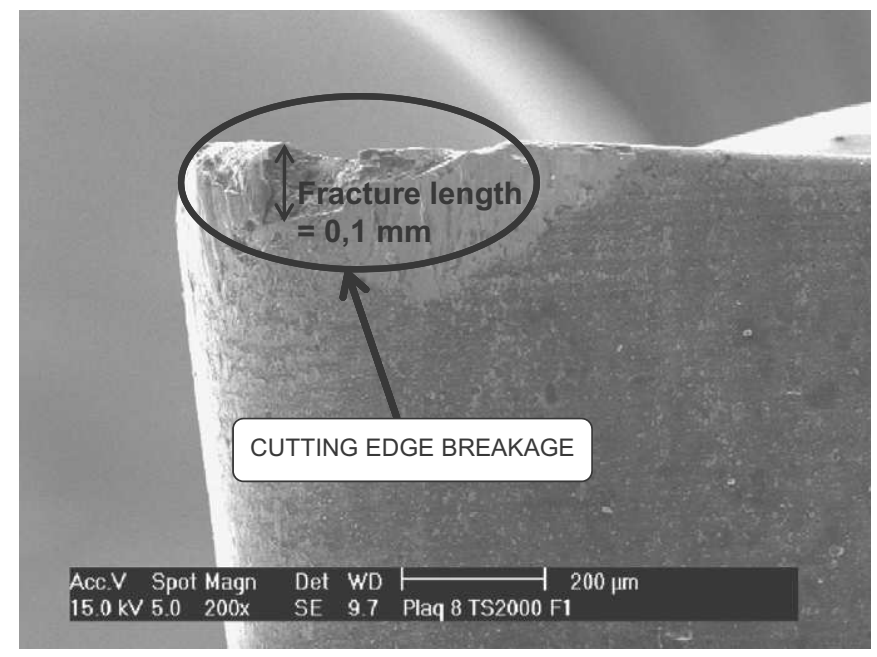

Fig. 7. Cutting edge breakage close to tool tip at secondary edge due to a previous chipping corresponding to $\mathrm{T}_{2}\left(\mathrm{E}_{1} \mathrm{TS} 2000 \kappa_{r} 0\right.$ ) worn insert tested with coolant at cutting speed of $50 \mathrm{~m} / \mathrm{min}$.

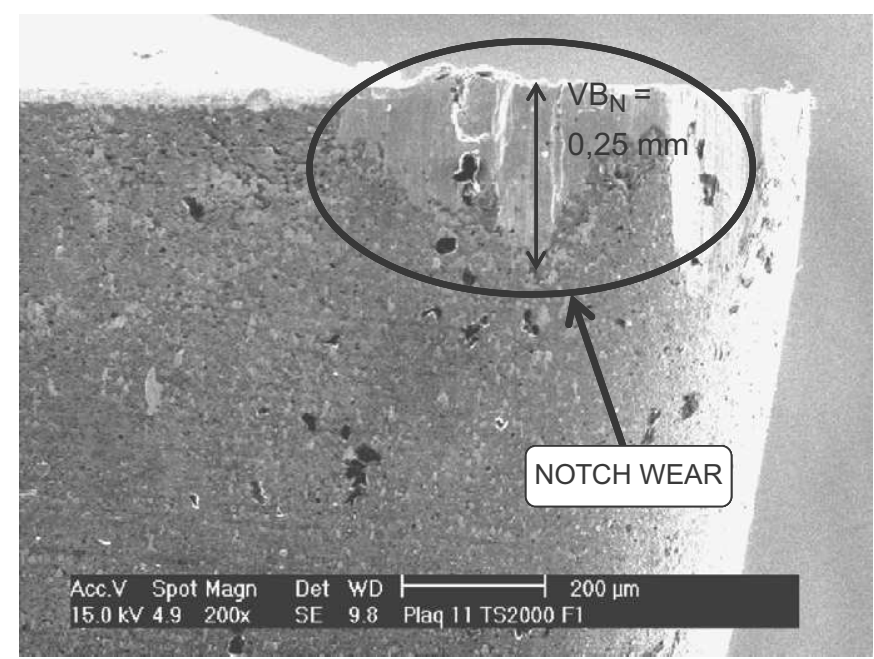

Fig. 8. Notch wear detail of $T_{2}\left(E_{1}\right.$ TS2000 $\left.\kappa_{r} 0\right)$ worn insert tested without coolant at cutting speed of $70 \mathrm{~m} / \mathrm{min}$.

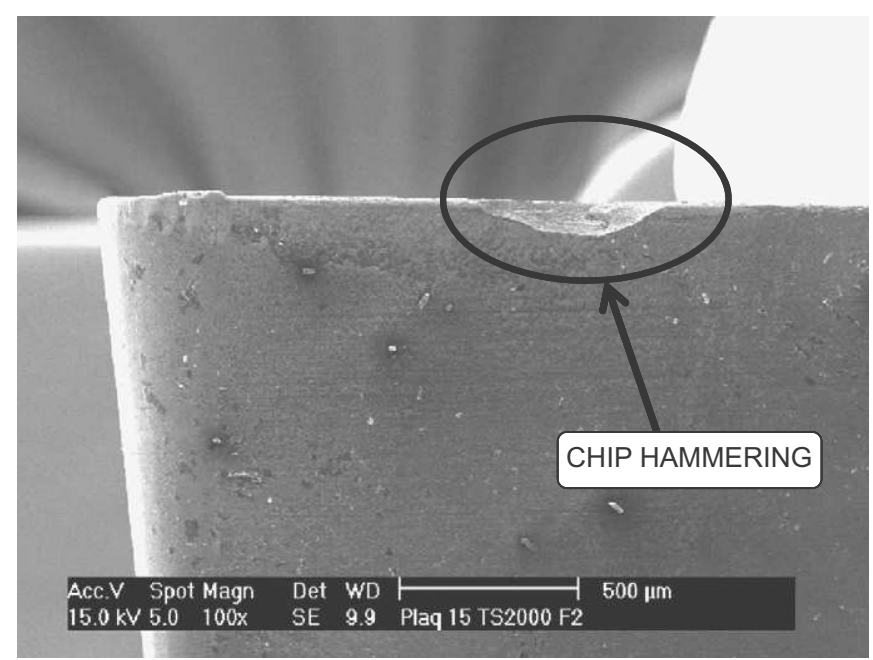

Fig. 9. Secondary cutting edge breakage due to chip hammering, corresponding to $\mathrm{T}_{3}\left(\mathrm{E}_{2} \mathrm{TS} 2000 \kappa_{r} 0\right)$ worn insert tested without coolant at cutting speed of $70 \mathrm{~m} / \mathrm{min}$.

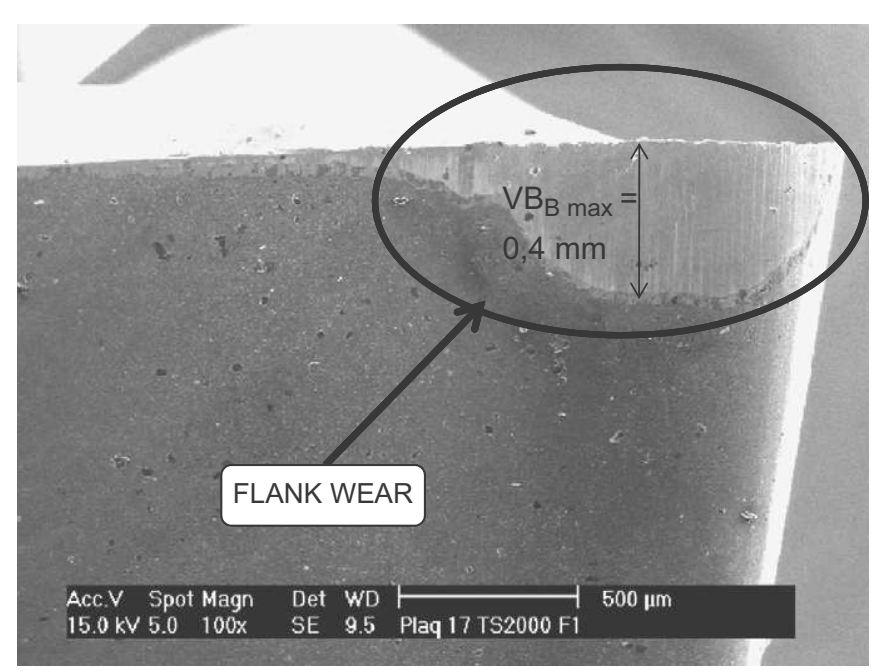

Fig. 10. Flank wear detail corresponding to $\mathrm{T}_{4}\left(\mathrm{E}_{1} \mathrm{TS} 2000 \kappa_{r} 45\right)$ worn insert tested with coolant at cutting speed of $50 \mathrm{~m} / \mathrm{min}$. 
In all cases tool life was lower than $10 \mathrm{~min}$ and notch wear was the dominant mechanism (notch equal or higher than $0.4 \mathrm{~mm}$ ).

Comparison between both edge geometries showed the competition between the advantages and drawbacks of the robust geometry $E_{2}$. The tool life in the case of robust geometry $E_{2}$ was higher than $E_{1}$ at cutting speed $70 \mathrm{~m} / \mathrm{min}$. On the other hand tool life for $E_{2}$ at cutting speed $50 \mathrm{~m} / \mathrm{min}$ was lower than $E_{1}$.

Table 4 summarizes observations concerning wear mechanisms of $\mathrm{T}_{3}$.

\subsubsection{Tool $T_{4}$ (TS2000 $\left.E_{1} \kappa_{r} 45\right)$}

As it was explained previously, the main wear mode observed for tool TS2000 F1 $\kappa_{r} 0^{\circ}$ was chipping and also significant notching was observed. The tougher substrate CP500 and the more robust edge configuration were selected in order to increase wear resistance. However in general tool lives did not increase. Stating a $\kappa_{r} 45^{\circ}$ diminishes 30\% the undeformed chip thickness with respect to $\kappa_{r} 0^{\circ}$. The cutting forces slightly increased (between 5 and $10 \%$ for fresh tool), however the pressure at the cutting edge was lowered. In consequence the trend to experience BUE and chipping at the cutting edge also diminished.

During cutting tests with $\kappa_{r} 45^{\circ}$ and cutting velocity $50 \mathrm{~m} / \mathrm{min}$ (both in dry conditions and using coolant) the tool did not suffer significant notch wear. Chipping appeared at relatively large cutting time (15 min with coolant and 12 min for dry conditions). Prevalent wear mode was flank wear in both cases, reaching $0.4 \mathrm{~mm}$ (end of tool life) for cutting time $30.5 \mathrm{~min}$ with coolant and $22 \mathrm{~min}$ in dry cutting, respectively. Flank wear is illustrated in Fig. 10.

The same behavior reported for tool $\mathrm{T}_{2}$ (only different from $\mathrm{T}_{4}$ because of the angle $\kappa_{r}$ ) is observed. When cutting speed increases from 50 to $70 \mathrm{~m} / \mathrm{min}$ chipping wear increases significantly being the predominant wear mode. In consequence the tool life is considerably reduced at cutting speed $70 \mathrm{~m} / \mathrm{min}$ when compared with tool life at $50 \mathrm{~m} / \mathrm{min}$.

During cutting tests with $\kappa_{r} 45^{\circ}$ and cutting velocity $70 \mathrm{~m} / \mathrm{min}$ (both in dry conditions and using coolant) tool life was slightly larger (6.5 min with coolant and 4 min for dry conditions) than

Roughness comparation T1 CP500 E1 Kr 0

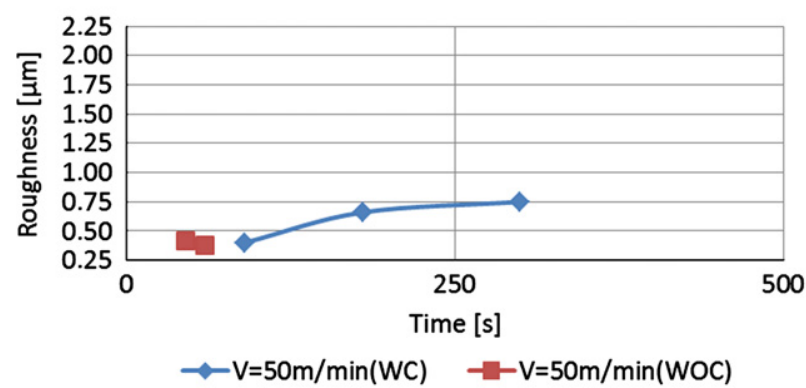

Roughness comparation T2 TS 2000 E1 Kr 0

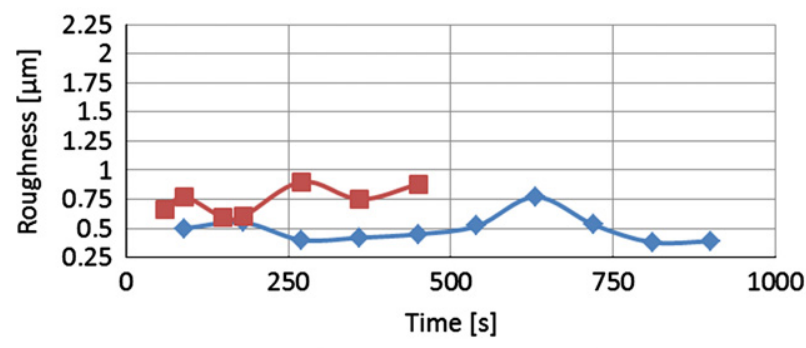

$\neg-\mathrm{V}=50 \mathrm{~m} / \mathrm{min}(\mathrm{WC}) \quad-\mathrm{C}-\mathrm{V}=50 \mathrm{~m} / \mathrm{min}(\mathrm{WOC})$ that exhibited by the same insert with $\kappa_{r} 0^{\circ}$. Chipping appeared in both cases leading to rapid cutting edge degradation. It was not observed relevant cutting edge breakage at the zone corresponding with the intersection between cutting edge and machined surface related with notching. Edge degradation caused vibrations and heating at the cutting zone, especially for dry cutting.

BUE was observed in all cases with $\kappa_{r} 0^{\circ}$ even at early stages of the test corresponding with low values of cutting time. However the tests performed with $\kappa_{r} 45^{\circ}$ only showed BUE at the highest velocity $(70 \mathrm{~m} / \mathrm{min})$ in dry conditions and at the final stages of the test, close to the end of tool life and simultaneously with high level of chipping. The degradation of the cutting edge affected also the clearance surface difficult and making difficult flank wear identification that was moderate at the zones slightly affected by chipping. No other test showed BUE formation for $\kappa_{r} 45^{\circ}$.

Table 5 summarizes main results obtained in this case.

\subsection{Surface roughness}

Surface roughness evolution with cutting time was checked both in dry conditions and using coolant (see Figs. 11 and 12). Surface roughness was obtained from five measurements of the average roughness $\left(R_{a}\right)$ at four different points in the surface (total number of measurements equal to 20). The surface roughness at the machined surface was taken as the maximum value of the twenty average roughness $\left(R_{a}\right)$ measurements. Maximum standard deviation of the measurements was $0.5 \mu \mathrm{m}$. According to International Standard Organisation ISO 4287, the evaluation length was set equal to $4 \mathrm{~mm}$ and the cut-off length was fixed equal to $0.8 \mathrm{~mm}$.

Small variations in $R_{a}$ can be observed for different tool configurations, probably due to the different edge geometry (chamfered or not) and to the different side cutting edge angle.

The level of roughness was maintained in a reasonably range both in dry and wet conditions. Main difference between the use of coolant and dry cutting are the dispersion of the results. Slightly higher values were observed in dry conditions and also dispersion was higher.

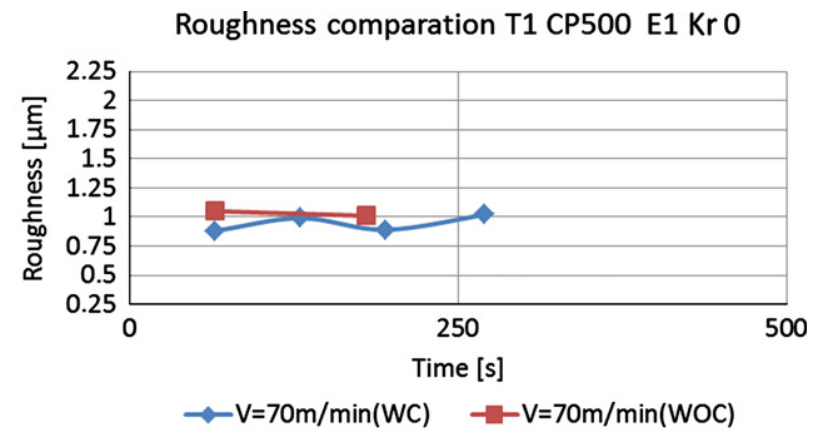

Roughness comparation T2 TS 2000 E1 Kr 0

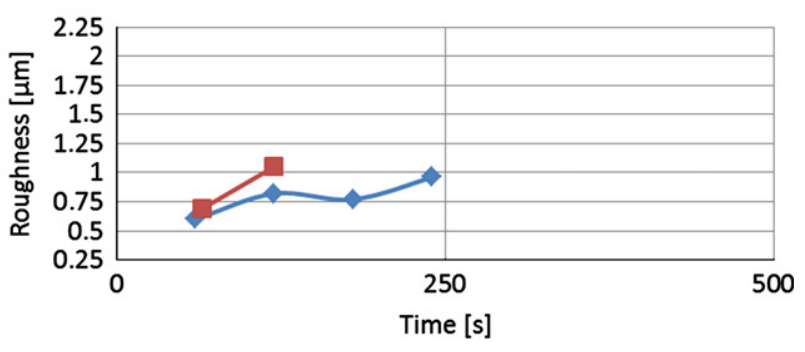

$\neg-\mathrm{V}=70 \mathrm{~m} / \mathrm{min}(\mathrm{WC}) \quad \rightarrow-\mathrm{V}=70 \mathrm{~m} / \mathrm{min}(\mathrm{WOC})$

Fig. 11. Roughness $\left(R_{a}\right)$ evolution vs. cutting time obtained with tools $T_{1}$ and $T_{2}$ with coolant (WC) and without coolant (WOC). 
Roughness comparation T3 TS2000 E2 Kr 0

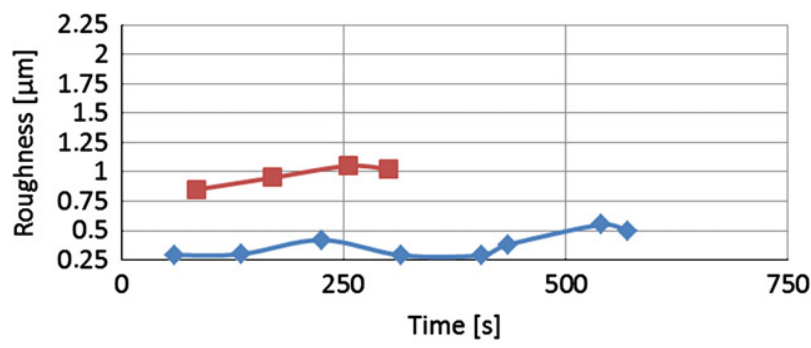

$\leadsto-\mathrm{V}=50 \mathrm{~m} / \mathrm{min}(\mathrm{WC}) \quad-\mathrm{E}=50 \mathrm{~m} / \mathrm{min}(\mathrm{WOC})$

Roughness comparation T4 TS 2000 E1 Kr 45

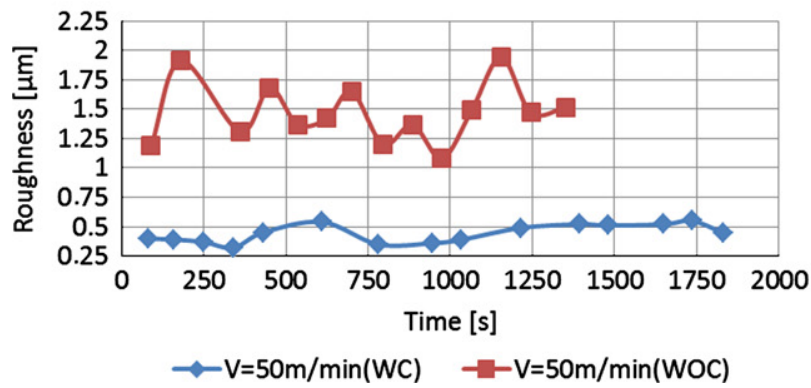

Roughness comparation T3 TS2000 E2 Kr 0

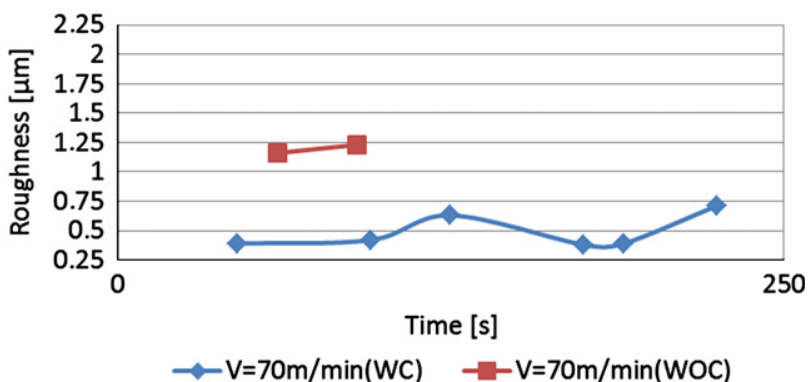

Roughness comparation T4 TS 2000 E1 Kr 45

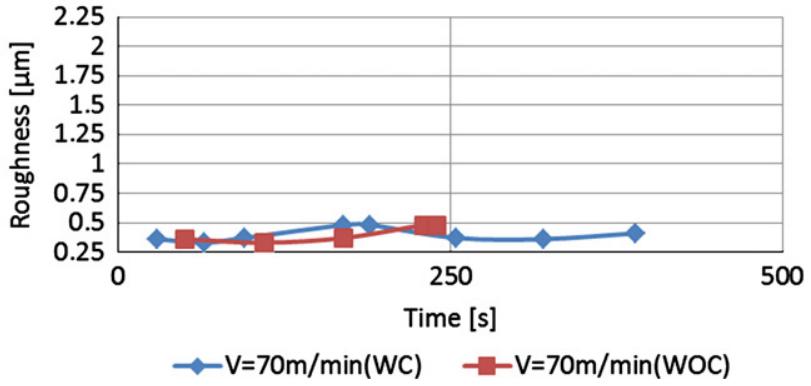

Fig. 12. Roughness $\left(R_{a}\right)$ evolution vs. cutting time obtained with tools $\mathrm{T}_{3}$ and $\mathrm{T}_{4}$ with coolant (WC) and without coolant (WOC).

\section{Conclusions}

Tool wear mechanisms during finishing turning of Inconel 718 have been analyzed in this paper. Tests were performed with coolant and also in dry conditions. Commercial inserts were tested and it was proved the feasibility of dry turning with the tools $\mathrm{T}_{3}$ and $\mathrm{T}_{4}$. Values of tool life are lower for dry conditions but they are still reasonable while roughness increased slightly.

Different coupled wear mechanisms were observed being especially significant notch wear due to high work hardening of the $\mathrm{Ni}$ alloy. Strong influence of the side cutting edge angle $\kappa_{r}$ in the wear evolution has been observed from experimental analysis: increasing $\kappa_{r}$ diminishes the cutting aggressiveness for the tool.

Some conclusions concerning the cutting behavior and wear mechanisms of the inserts tested in turning Inconel 718 can be established from this work:

- Tool $\mathrm{T}_{1}$ (substrate CP500, $\mathrm{E}_{1}, \kappa_{r} 0$ ): Dominant wear mode was notching in all conditions tested and reduced tool life was observed (lower than $5 \mathrm{~min}$ in all cases). This material is not proper for machining Inconel 718 in the conditions involved in the tests.

- Tool $\mathrm{T}_{2}$ (substrate TS2000, $\mathrm{E}_{1}, \kappa_{r} 0$ ): It was observed significant level of BUE, chipping and notch wear in all tests. Moreover in dry turning also flank wear occurred due to the enhanced temperature. Flank wear caused tool life termination at cutting speed $50 \mathrm{~m} / \mathrm{min}$ in dry conditions for cutting time $9 \mathrm{~min}$. For higher velocity equal to $70 \mathrm{~m} / \mathrm{min}$ strong chipping caused tool breakage in 2 min and did not allow the flank wear to evolve. The use of coolant increased tool life (15 and $5 \mathrm{~min}$ for low and high velocity respectively), however the breakage due to chipping also occurred.

- Tool $\mathrm{T}_{3}$ (substrate TS2000, $\mathrm{E}_{2}, \kappa_{r} 0$ ): The same wear patterns as those reported for edge configuration $\mathrm{E}_{1}$ were observed: BUE, chipping and notch wear, and tool lives are comparable. However, the use of the robust edge configuration $\mathrm{E}_{2}$ increases edge resistance to chipping, while notch wear was dominant leading to tool lives lower than $10 \mathrm{~min}$ in all cases.
- Tool T 4 (substrate TS2000, $\mathrm{E}_{1}, \kappa_{r} 45$ ): The increment of $\kappa_{r}$ lead to diminish undeformed chip thickness and in consequence pressure at the cutting edge. Lower pressure diminished chipping wear and avoided BUE and notching. During tests at high velocity $70 \mathrm{~m} / \mathrm{min}$ (both with and without coolant) chipping occurred since early stages of the test leading to edge breakage at cutting time around $5 \mathrm{~min}$. At low cutting speed $50 \mathrm{~m} / \mathrm{min}$ tool life increased significantly up to $30.5 \mathrm{~min}$ and $22 \mathrm{~min}$ in the tests with and without coolant respectively. Flank wear was dominant in both conditions.

\section{Acknowledgments}

The authors are indebted for the financial support of this work, to the Ministry of Economy and Competitiveness of Spain (under project DPI2008-06746)

\section{References}

[1] E.O. Ezugwu, Key improvements in the machining of difficult-to-cut aerospace superalloys, International Journal of Machine Tools and Manufacture 45 (12-13) (2005) 1353-1367.

[2] Chao Xue, Wuyi Chen, Adhering layer formation and its effect on the wear of coated carbide tools during turning of a nickel-based alloy, Wear 270 (2011) 895-902.

[3] A. Muñoz-Sánchez, J.A. Canteli, J.L. Cantero, M.H. Miguélez, Numerical analysis of the tool wear effect in the machining induced residual stresses, Simulation Modelling Practice and Theory 19 (2) (2011) 872-886.

[4] S. Olovsjö, L. Nyborg, Influence of microstructure on wear behaviour of uncoated WC tools in turning of Alloy 718 and Waspaloy, Wear 282-283 (2012) 12-21.

[5] A. Altin, M. Nalbant, A. Taskesen, The effects of cutting speed on tool wear and tool life when machining Inconel 718 with ceramic tools, Materials Design 28 (2007) 2518-2522.

[6] R.M. Arunachalam, M.A. Mannan, A.C. Spowage, Residual stress and surface roughness when facing age hardened Inconel 718 with CBN and ceramic cutting tools, International Journal of Machine Tools and Manufacture 44 (2004) 879-887.

[7] J.P. Costes, Y. Guillet, G. Poulachon, M. Dessoly, Tool-life and wear mechanisms of CBN tools in machining of Inconel 718, International Journal of Machine Tools and Manufacture 47 (2007) 1081-1087. 
[8] I.M. Hutchings, Tribology: Friction and Wear of Engineering Materials, Edward Arnold, Great Britain, 1992.

[9] D. Dudzinski, A. Devillez, A. Moufki, D. Larrouquère, V. Zerrouki, J. Vigneau, A review of developments towards dry and high speed machining of Incone 718 alloy, International Journal of Machine Tools and Manufacture 44 (2004) 439-456.

[10] E.O. Ezugwu, Z.M. Wang, A.R. Machado, The machinability of nickel-based alloys: a review, Journal of Materials Processing Technology 86 (1999) 1-16.

[11] E.O. Ezugwu, I.R. Pashby, High speed milling of nickel-based superalloys, Journal of Materials Processing Technology 3 (1992) 429-437.

[12] M. Rahman, W.K.H. Seah, T.T. Teo, The machinability of Inconel 718, Journal of Materials Processing Technology 63 (1997) 199-204.

[13] A. Bhatt, H. Attia, R. Vargas, V Thomson, Wear mechanisms of WC coated and uncoated tools in finish turning of Inconel 718, Tribology International 43 (2010) 1113-1121

[14] J. Endrino, G.S. Fox-Rabinovich, C. Gey, Hard AlTiN, AlCrN PVD coatings for machining of austenitic stainless steel, Surface and Coatings Technology 200 (24) (2006) 6840-6845.

[15] K. Kutschej, P.H. Mayrhofer, M. Kathrein, P. Polcik, C. Mitterer, A new lowfriction concept for Ti1- $x$ Al $x \mathrm{~N}$ based coatings in high-temperature applications, Surface and Coatings Technology 188-189 (2004) 358-363.

[16] P.C. Jindal, A.T. Santhanam, U. Schleinkofer, A.F. Shuster, Performance of PVD, TiN, TiCN, and TiAlN coated cemented carbide tools in turning, International Journal of Refractory Metals and Hard Materials 17 (1999) 163-170.

[17] J.L. Cantero, M.M. Tardío, J.A. Canteli, M. Marcos, M.H. Miguélez, Dry drilling of alloy Ti-6Al-4V, International Journal of Machine Tools and Manufacture 45 (2005) 1246-1255.
[18] S.C. Veldhuis, G.K. Dosbaeva, K. Yamamoto, Tribological compatibility and improvement of machining productivity and surface integrity, Tribology International 42 (6) (2009) 1004-1010.

[19] B. Gakovic, C. Radu, M. Zamfirescu, B. Radak, M. Trtica, S. Petrovic, P. Panjan, F. Zupanic, C. Ristoscu, I.N. Mihailescu, Femtosecond laser modification of multilayered TiAlN/TiN coating, Surface and Coatings Technology (2011), http://dx.doi.org/10.1016/j.surfcoat.2011.07.042.

[20] K.-D. Bouzakis, N. Michailidis, N. Vidakis, G. Erkens, Interpretations of PVD coated inserts wear phenomena in turning, Annals of the CIRP 49 (1) (2000) 65-68.

[21] A. Devillez, F. Schneider, S. Dominiak, D. Dudzinski, D. Larrouquere, Cutting forces and wear in dry machining of Inconel 718 with coated carbide tools, Wear 262 (2007) 931-942.

[22] L. Settineri, M.G. Faga, B. Lerga, Properties and performances of innovative coated tools for turning inconel, International Journal of Machine Tools and Manufacture 48 (2008) 815-823.

[23] A. Devillez, G. Le Coz, S. Dominiak, D. Dudzinski, Dry machining of Incone 718 , workpiece surface integrity, Journal of Materials Processing Technology 211 (2011) 1590-1598.

24] Seco, Turning Catalogue, Seco Tools, 2009.

25] K.A. Kadirgama, M.M. Abou-El-Hossein Noor, K.V. Sharma, B. Mohammad, Tool life and wear mechanism when machining Hastelloy C-22HSK, Wear 270 (2011) 258-268.

[26] E.O. Ezugwu, Z.M. Wang, Performance of PVD and CVD coated tools when machining nickel-based, Inconel 718 alloy, in: N. Narutaki, et al., (Eds.) Progress of Cutting and Grinding, vol. 111, 1996, pp. 102-107.

[27] J. Aucote, S.R. Foster, Performance of sialon cutting tools when machining nickel-base aerospace alloys, Materials Science and Technology 2 (2) (1986) 700-708. 